\title{
Doğrultu Atımlı Fay Sistemlerindeki Traverten Oluşumlarının Jeolojik, Tektonik, Jeokimyasal ve Jeokronolojik Özelliklerine Sivrice (Elazı̆̆) Güneybatısı'ndan Bir Örnek
}

Geological, Tectonic Geochemical and Geochronological Properties of Travertine Occurrences Along the Strike-Slip Fault Systems:A Case From Southweatern Part of Sivrice (Elazığ)

\section{Serap ÇOLAK EROL}

Fırat Üniversitesi, Mühendislik Fakültesi, Jeoloji Mühendisliği Bölümü, 23119, Elazlğ

e-posta:serapcolak@firat.edu.tr

Öz

Türkiye'nin en önemli ikinci neotektonik yapısı olan sol yanal doğrultu atımlı Doğu Anadolu Fay Sistemi'nin önemli zonlarından biri olan Sivrice Fay Zonu üzerinde ve Sivrice İlçesi’nin (Elazı̆̆) 20 km GB'sında yer alan traverten yüzleği, güney-güneydoğuya bakan duraysız bir yamaç üzerinde, yamaç topoğrafyasına uyumlu olarak depolanmıştır.

Traverten yüzleğinin üzerinde yer aldığı Orta Eosen yaşlı Maden Grubu, esas olarak volkanik ara katkılı çamurtaşları ile andezit, bazalt ve bunları kesen diyabaz dayklarından oluşur. Traverten oluşumunda ana kaya rolü üstlenen Pütürge Metamorfitleri ise Sivrice çevresindeki yüzleklerinde, kalkşist ve mermerlerle temsil edilir. Pütürge Metamorfitleri'nin litolojisi ve sol yanal doğrultu atımlı Sivrice Fay Zonu'nun oluşturduğu kırıklı yapı, akışkan dolaşımında ve dolayısıyla travertenlerin oluşumunda önemli rol oynamıştır. Traverten yüzleği, normal bileşenli sol yanal doğrultu atımlı faylar boyunca, fayların ve ana kayanın oluşturduğu uygun koşullarda yüzeye kadar çıkan sular tarafından fay önünde çökeltildiğinden, travertenlerin morfolojik sınıflamasına göre ‘fay önü traverteni’ olarak değerlendirilmiştir.

Traverten örneklerinin element oranları, Ca: 378216-385220 ppm, Mg: 5428-8021 ppm, Sr: 2133-6046 ppm mertebesindedir. $\delta^{13} \mathrm{C}$ değerleri, $+3,5$ ile $+6,7$ (\%o PDB), $\delta^{18} \mathrm{O}$ değerleri ise -8.1 ile -9.6 (\%o PDB) arasındadır. Bu jeokimyasal verilere göre incelenen travertenler, termojen kökenlidir. Travertenlerden elde edilen U-Th yaş verilerine göre, traverten sahasında günümüzden en azından $30.86 \pm 0.49$ önce traverten çökelimi başlamıştır.

Anahtar kelimeler: Doğu Anadolu Fay Sistemi, fay önü traverteni, sol yanal doğrultu atımlı fay, U-Th yaşlandırması 


\section{ABSTRACT}

The East Anatolian fault system (EAFS) of left lateral strike-slip is the second most important neotectonic structure of Turkey. The travertine occurrence is located on the Sivrice fault zone, which is one the significant zone of the EAFS and precipitated on a $S$ to $S W$-facing slope, $20 \mathrm{~km} \mathrm{SW}$ of the Sivrice town (Elazığ) in accordance with the slope topography.

The Maden Group of Middle Eocene age, on which the travertine occurrence took place, composed mostly of mudstones with volcanic intercalations, andesite, basalt and diabase dykes that cut them. The Pütürge Metamorfics that play role as a basement rock are represented by calcschist and marble around their Sivrice exposures. Lithology of the Pütürge Metamorfics and the fractured structure of the left lateral strike-slip Sivrice Fault Zone play an important role on the travertine formation. As the travertine exposures has been precipitated under appropriate conditions that formed by faults and bedrock in front of a fault along the left lateral strike-slip fault zone with normal component, they have been evaluated as 'fault-front travertines' depending on the morphological classification.

The most abundant element concentrations of the travertine samples are: Ca: 378216-385220 ppm, Mg: 5428-8021 ppm, Sr: 2133-6046 ppm. The $\delta^{13} \mathrm{C}$ values range from $+3,5$ to $+6,7$ (\%o PDB), while the $\delta^{18} \mathrm{O}$ values are between -8.1 and -9.6 (\% PDB). These geochemical signatures indicate that the travertines studied are of thermogene origin. Travertine precipitation began at least $30.86 \pm 0.49$ ka ago with respect to today in the field based on the U-Th age data.

Key Words: Left lateral strike-slip fault, range-front travertine, The East Anatolian Fault System, U-Th dating

\section{GíRİ̧}

Traverten terimi için birçok araştırmacı, birbirine benzeyen tanımlar yapmış olmakla birlikte (Bates ve Jackson, 1980; Julia, 1983; Chafetz ve Folk, 1984; Wyatt, 1986; Guo ve Riding, 1998) genel olarak traverten, karstik ve sıcak su kaynakları çevresinde, küçük nehirler ve bataklıklarda oluşabilen, kimyasal ve/veya biyokimyasal yolla çökelebilen sık dokulu kalsiyum karbonat $\left(\mathrm{CaCO}_{3}\right)$ birikimleridir. Travertenlerin birincil minerali, kalsittir.

Barnes vd. (1978)'in belirttiği gibi, tektonik olarak aktif olan zonlar ile traverten çökelimi arasında dünya çapında çok yakın bir ilişki vardır. Çünkü faylanmalar, hidrotermal akışkanın yüzeye taşınmasında önemli rol oynarlar (Sibson vd., 1975). Dolayisiyla travertenler, bölgesel tektoniğin bazı belirtilerini yansıtırlar. Birçok traverten kütlesi, Pleyistosen'den bu yana oluşmaya devam ettiğinden (Schwarcz ve Latham, 1984; Goff ve Shevenell, 1987; Kronfeld vd., 1988; Heimann ve Sass, 1989), aktif ve aktif olmayan travertenlerin varlığ 1 , tektonik aktivitenin günümüzde veya yakın geçmişte devam ettiğinin bir göstergesidir. Travertenler, çökelme sirası ve sonrasına ait tektonik kayıtları içerdiğinden, çökelme sırasındaki ve sonrasındaki tektonizma hakkında önemli bilgiler sağlar (Altunel, 1996).

Doğu Anadolu Fay Sistemi (DAFS), kuzeydoğuda Karlıva (Bingöl) ile güneybatıda Akdeniz arasında uzanan, ülkemizin depremselliği açısından en önemli fay sistemlerinden biridir. Fay sistemi, Arap-Afrika plakaları ile Anadolu bloğu arasında ortaya çıkan etkileşimi yanal bir hareketle karşılamaktadır (Arpat ve Şaroğlu, 1972; Jackson ve McKenzie, 1984; Şengör vd., 1985; Gülen vd., 1987; Muehlberger ve Gordon, 1987; Lyberis vd., 1992; Şaroğlu vd., 1992b; Westaway, 1994; 
Westaway, 2003; Gürsoy vd., 2003). Bu özelliği ile Doğu Akdeniz'in en önemli aktif tektonik yapılarından olan fay sistemi, günümüze kadar birçok araştırmacı tarafından farklı disiplinler kullanılarak çalışılmıştır.

Faylar ile travertenler arasındaki ilişki, Türkiye'de de birçok araştırmacı tarafından incelenmiştir (Altunel ve Hancock (1993a, b), Altunel (1994, 1996), Çakır (1996, 1999), Ayaz (1998), Karabacak (2002), Özkul vd. (2010, 2013, 2014), Mesci (2004, 2013b), Mesci vd. (2008), Uysal vd. (2007, 2009), Çolak Erol vd. (2015)).

\section{JEOLOJİK-TEKTONIKK ÖZELLİKLER}

Çalışma konusu olan traverten yüzleği, Sivrice İlçesi'nin (Elazığg) 20 km GB'sında yer alan K1lıçkaya Köyü yakın GD'sunda yüzeyler (Şekil $1,2)$. Traverten yüzleği, deniz seviyesi üzerinde 750 ila 950 metreler arasında, güney-güneydoğuya bakan duraysız bir yamaç üzerinde, yamaç topoğrafyasına uyumlu olarak depolanmıştır.

Traverten yüzleğinin üzerinde geliştiği Bingöl-Yarpuzlu Segmenti Doğu Anadolu Fay Sistemi'nin en uzun yapısal bölümü olup K50 D doğrultusundadır (Şekil 1). Kuzeydoğuda Bingöl Şehri'nin 10 km kadar kuzeybatısında Çevrimpınar Köyü yakınından başlar ve güneybatıya doğru yaklaşık 180 km devam ederek Yarpuzlu Köyü'ne (Sincik, Adıyaman) kadar uzanır.

Traverten depolanmasının üzerinde yer aldığı, Bingöl-Yarpuzlu Segmenti'ne ait olan ve DAFS'nin ana fayını içeren Sivrice Fay Zonu (SFZ), 2-4 km genişliğinde, $180 \mathrm{~km}$ uzunluğundadır ve birkaç alt fay kuşağı ile çok sayıda tekil faya ayrılır (Şekil 1). Sahip olduğu bu yapısal özelliği, 5 km genişlikte, $32 \mathrm{~km}$ uzunlukta, kenarları önemli miktarda normal atım bileşenli olan, kısa ve uzun bir seri fay ile sınırlanmış, günümüzde büyümesini sürdüren, bir bölümünde Hazar Gölü’nü de bulunduran mercek biçimli bir çöküntü oluşturur. Aksoy vd. (2007), Sivrice Fay Zonu boyunca birikmiş olan sol yanal doğrultu atım ve düşey atım miktarlarını sırasıyla $9 \pm 1 \mathrm{~km}$ ve $1317 \pm 10$ m olarak belirtmişlerdir. Bu değerler, Sivrice Fay Zonu üzerindeki yıllık yanal ve düşey kayma hızlarının sırasıyla $4 \mathrm{~mm} / \mathrm{y} 1 \mathrm{l}$ ve $0,5 \mathrm{~mm} /$ y1l olduğunu gösterir. Ancak, DAFS üzerindeki kayma hızları, bu değerlerden çok daha büyüktür; çünkü DAFS, Hazar Gölü bölgesinde, pek çok fay zonundan oluşmakta ve kayma hızları yalnızca Sivrice Fay Zonu tarafindan değil, tüm fay zonları tarafindan bölüşülmektedir. $\mathrm{Bu}$ değerlerden de anlaşılacağı üzere Doğu Anadolu Fay Sistemi’nin kuzeydoğu bölümünü oluşturan fay zonları veya tekil faylar, özellikle doğrultu atım havzalarının iyi geliştiği alanlarda önemli oranda düşey bileşene de sahiptir. Bu bileşenin varlığı ve oranı, doğrultu atımlı tektonik rejim içinde genişleme alanları oluşturmaktadır.

Söz konusu traverten depolanmas1, Orta Eosen yaşlı Maden Grubu üzerinde yer almaktadır. Paleozoyik-Mesozoyik yaşlı Pütürge Metamorfitleri ile Orta Eosen yaşlı Maden Grubu, Kılıçkaya Köyü çevresinde yüzeyleyen birimlerdir (Şekil 3, 4, 5).

Traverten oluşumunda ana kaya rolü üstlenen Pütürge Metamorfitleri'nin metamorfizma özellikleri birbirinden farklı olan alt ve üst grup ya da alt ve üst birlik olarak adlandırılan iki bölümden oluştuğu kabul edilir (Sungurlu vd., 1985; Erdem, 1994). Alt grup ya da birlik; gözlü gnays, biyotit şist ve amfibol şist, amfibolit ve granitik gnayslardan oluşurken, üst grup ya da birlik ise muskovit şist, granatlı mika şistler, kalkşist ve mermerlerden oluşur. Kılıçkaya Köyü çevresindeki yüzleklerinde Pütürge Metamorfitleri, üst birliğe ait kalkşist ve mermerlerle temsil edilir.

Temel kaya olan Orta Eosen yaşlı Maden Grubu ise, söz konusu traverten yüzleği çevresinde, esas olarak volkanik ara katkılı bordoşarabi renkli çamurtaşları ile andezit, bazalt ve 
bunları kesen diyabaz dayklarından oluşur (Çelik, 2003).

Maden Grubu'na (Tm) ait kayaçlar, Değirmen Dere Vadisi'ni denetleyen Sivrice Fay Zonu'nun ana kırığı boyunca Pütürge Metamorfitleri ile yan yana görülür (Şekil 6). Pütürge Metamorfitleri'nin litolojisi ve sol yanal doğrultu atımlı Sivrice Fay Zonu'nun oluşturduğu kırıklı yapının, travertenlerin oluşumunda önemli rol oynadığı düşünülmektedir. Söz konusu traverten yüzleği, Sivrice Fay Zonu'nu oluşturan faylar boyunca, fayların ve ana kayanın oluşturduğu uygun koşullarda yüzeye kadar çıkan sular tarafından fay önünde çökeltilmiştir. $\mathrm{Bu}$ durumda traverten yüzleğini, morfolojik siniflamaya göre (Chafetz ve Folk, 1984; Altunel ve Hancock, 1993a; Altunel, 1996; Ayaz, 2002a), fay önü traverteni olarak değerlendirebiliriz (Şekil 3b, 5). Traverten oluşumu, SFZ ana kırığına paralel olan Y kırığı üzerinde gelişmiştir (Şekil 3c).

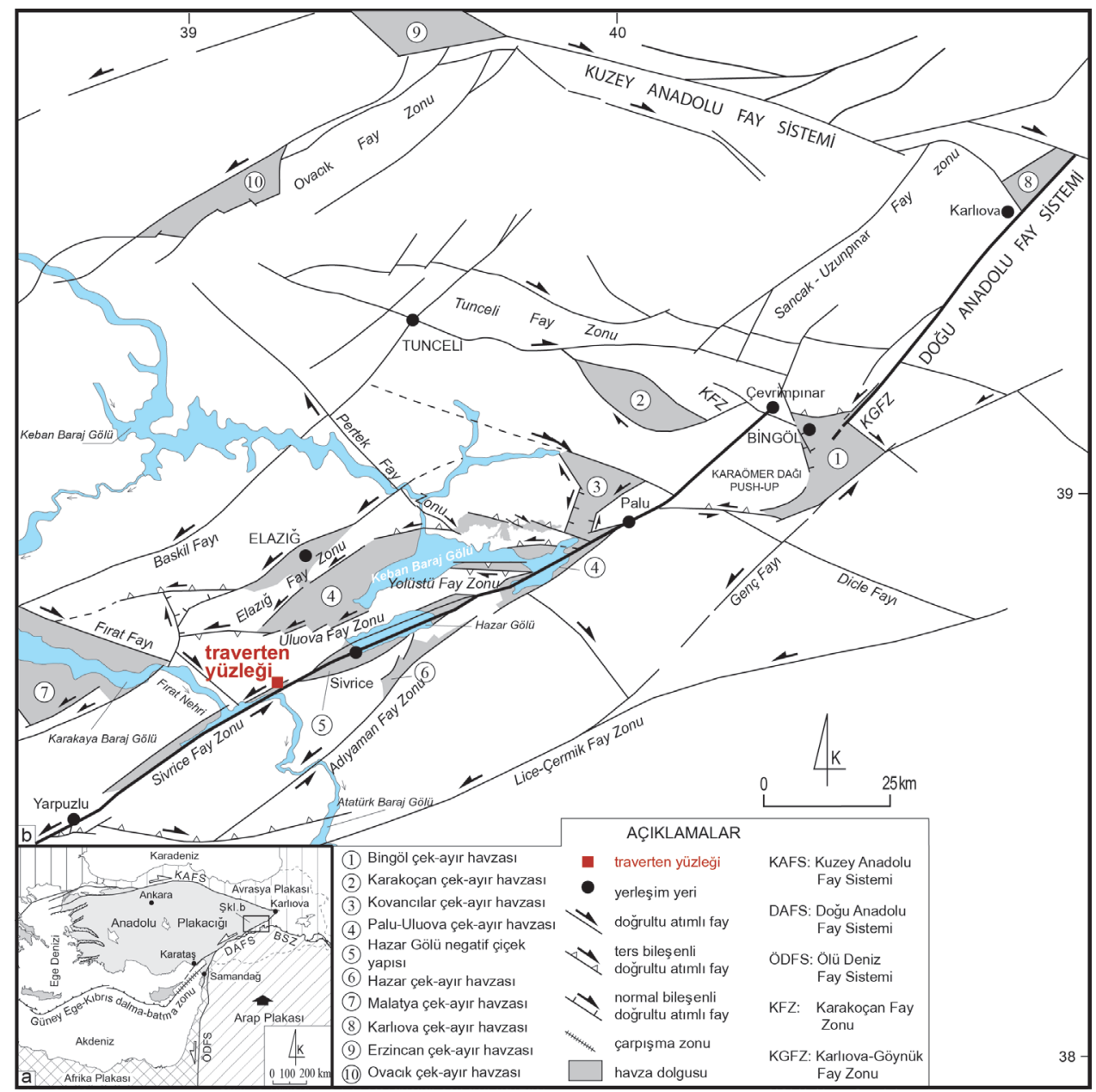

Şekil 1. İnceleme alanının konumunu gösteren harita. a-Doğu Akdeniz Bölgesi’nin ana levhaları ve bunları sınırlayan fayları gösteren sadeleştirilmiş harita; b-İnceleme alanının konumu ve Bingöl-Elazı̆̆ çevresinde Doğu Anadolu Fay Sistemi'ni oluşturan ana fay zonları ve doğrultu atım havzalarını gösteren sadeleştirilmiş tektonik harita (Koçyiğit vd., 2003'den değiştirilerek)

Figure 1. Location map of investigated area. a-Simplified map showing major plates and their boundary faults in East Mediterranean surrounding areas; $b$-simplified map showing strike-slip basins and major fault zones of the East Anatolian Fault System around Bingöl-Elazlğ (modified from Koçyiğit et al. 2003) 


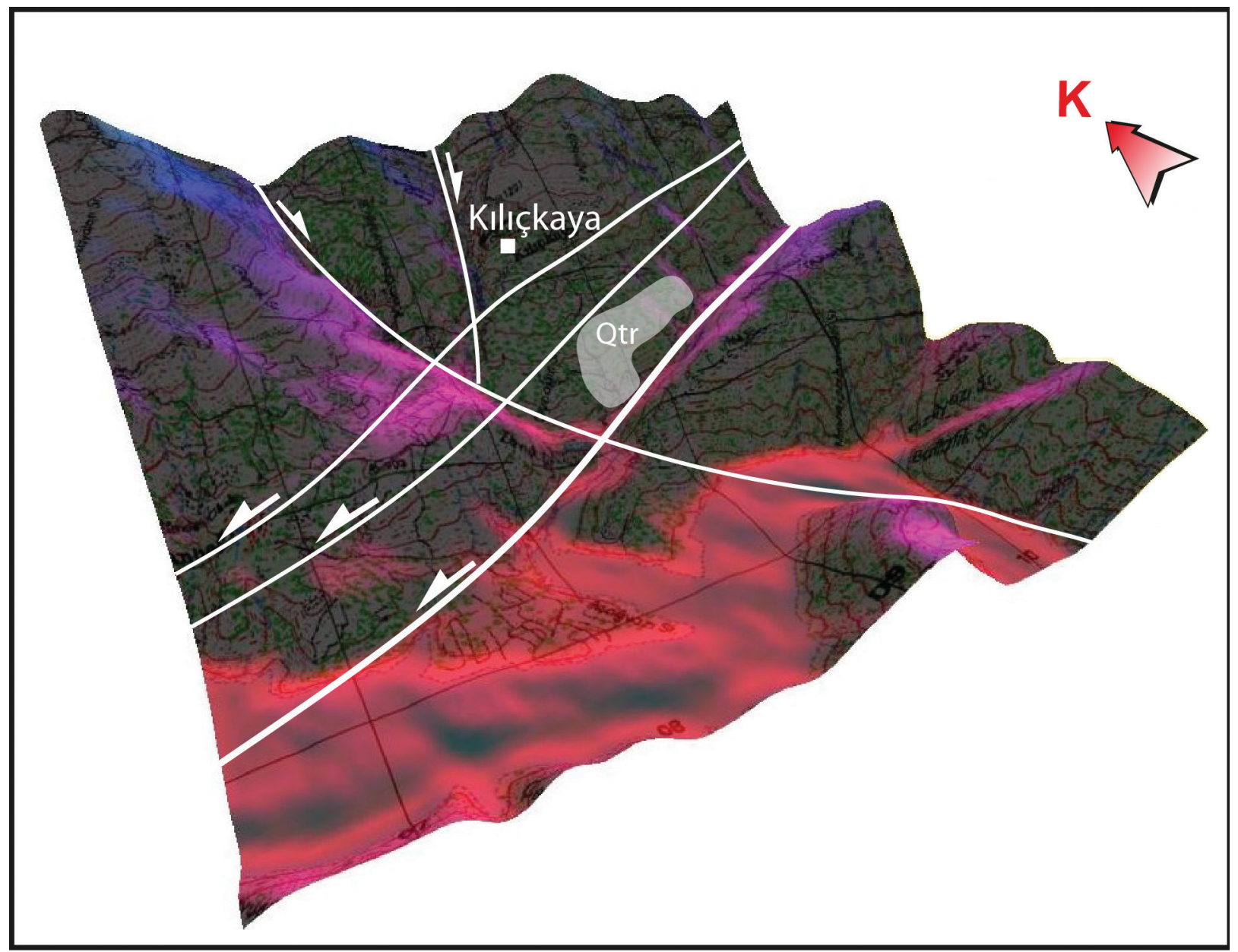

Şekil 2. Kılıçkaya Köyü ve çevresi tektoniğinin DEM üzerinde gösterimi. Qtr: traverten yüzleği

Figure 2. DEM image and tectonic of Kllıçkaya Village and surroundings area. Qtr: travertine

\section{DEPOLANMA ÖZELLIKKLERİ}

Traverten yüzleği, güney-güneydoğuya bakan bir yamaç üzerinde, yamaç topoğrafyasına uyumlu olarak depolanmıştır (Şekil 7). Tabanındaki ana kaya üzerinde, ana kayadan türemiş çakıl boyutundaki parçaları içeren kırıntılı bir seviye ile uyumsuz olarak başlar (Şekil 8a, b) ve bu kırıntılı seviye yukarıya doğru, yerini önce ince tabakalı, daha üstlere doğru ise kalın tabakalı-masif traverten düzeylerine bırakır (Şekil 8a).

\section{MINERALOJIKK BİLEŞİM VE ELEMENT JEOKIMYASI}

Mineralojik olarak travertenler $\mathrm{CaCO}_{3}$ '1n iki ana polimorfundan birisi olan kalsitten oluşur. Ancak, bazı durumlarda bu iki mineral dışında dolomit, barit vb. mineraller de oluşumda yer alabilirler (Pentecost, 2005; Özkul vd. 2013). Kılıçkaya sahasından alınan 3 adet traverten örneği, XRD analiz sonuçlarına göre tamamen kalsitten oluşmaktadır. Örneklerde, eser miktarda kuvars tespit edilmiştir (Şekil 9). 
Kilıçkaya travertenlerine ait 5 adet örneğin element konsantrasyonları, Çizelge 1'de verilmiştir. Buna göre Ca: 378216-385220 ppm, Sr: 2133-6046 ppm ve Mg: 5428-8021 ppm mertebesindedir.

Travertenlerin Sr konsantrasyonları ile mineralojik bileşimleri arasında yakın bir ilişki olduğu birçok çalışmada bildirilmiştir (Folk, 1994; Fouke vd., 2000; Pentecost, 2005; Kele vd., 2008, 2011). Çoğunlukla kalsit bileşimli olan meteojen travertenler (tufalar), genellikle 20-200 ppm gibi düşük Sr değerleri sunarlar. Buna karşılık, İtalya'da olduğu gibi, aragonit bileşimli termojen travertenlerde 9500 ppm'e kadar $\mathrm{Sr}$ değerleri rapor edilmiştir (Cipriani vd., 1977; Duchi vd., 1978). Karlıva (Bingöl) yakınlarındaki kalsit bileşimli Hacılar sırt tipi travertenlerinin $\mathrm{Sr}$ içerikleri çok yüksek olup, 7104 ppm ile 16292 ppm arasında değişmektedir (Aksoy vd., 2011; Çolak Erol, 2014). Diğer taraftan, Pamukkale'de kalsit bileşimli güncel yamaç travertenlerinde ise 3028 ppm Sr belirlenmiştir (Özkul vd., 2013). K1lıçkaya sahasının 2133-6046 ppm'lik yükssek Sr değerleri, oldukça derin dolaşımlı sıcak sulardan çökelen termojen kökenli bir traverten oluşumunu işaret eder.

Termojen travertenlerde Kilıçkaya travertenlerinin $\mathrm{Mg}$ değerleri de yüksek olup, 5428-8021 ppm arasındadır. Yüksek Fe ve $\mathrm{Mg}$ oranlar1, hidrotermal suların şist ve ofiyolitik kayaçlarla etkileşiminin bir sonucu olduğu düşünülmektedir.

\section{DURAYLI İZOTOP BİLEŞİMI}

Termojen ve meteojen travertenlerin duraylı izotop kayıtları farklılık gösterir. Termojen travertenler daha çok pozitif değerler sunarken, meteojen travertenler negatif değerler sunar (Pentecost, 2005). Pozitif $\delta^{13} \mathrm{C}$ değerleri, magmatik faaliyetlerin yanı sıra termometamorfik süreçler sonucu açığa çıkmış $\mathrm{CO}_{2}$ 'in katkısına işaret eder. Oysa negatif $\delta^{13} \mathrm{C}$ değerleri, muhtemelen derin kaynaklı $\mathrm{CO}_{2}$ ile toprak zonundan türemiş $\mathrm{CO}_{2}{ }_{2}$ in karışmasından ortaya çıkar.

Kılıçkaya traverten örneklerinin $\delta^{13} \mathrm{C}$ değerleri, $+3,5$ ila $+6,7$ (\% PDB), $\delta^{18} \mathrm{O}$ değerleri ise -8.1 ila -9.6 (\%o PDB) arasındadır (Çizelge 2; Şekil 10). Bu değerler çalışılan travertenlerin termojen kökenli olduğuna ilişkin kuvvetli bir kanittır.

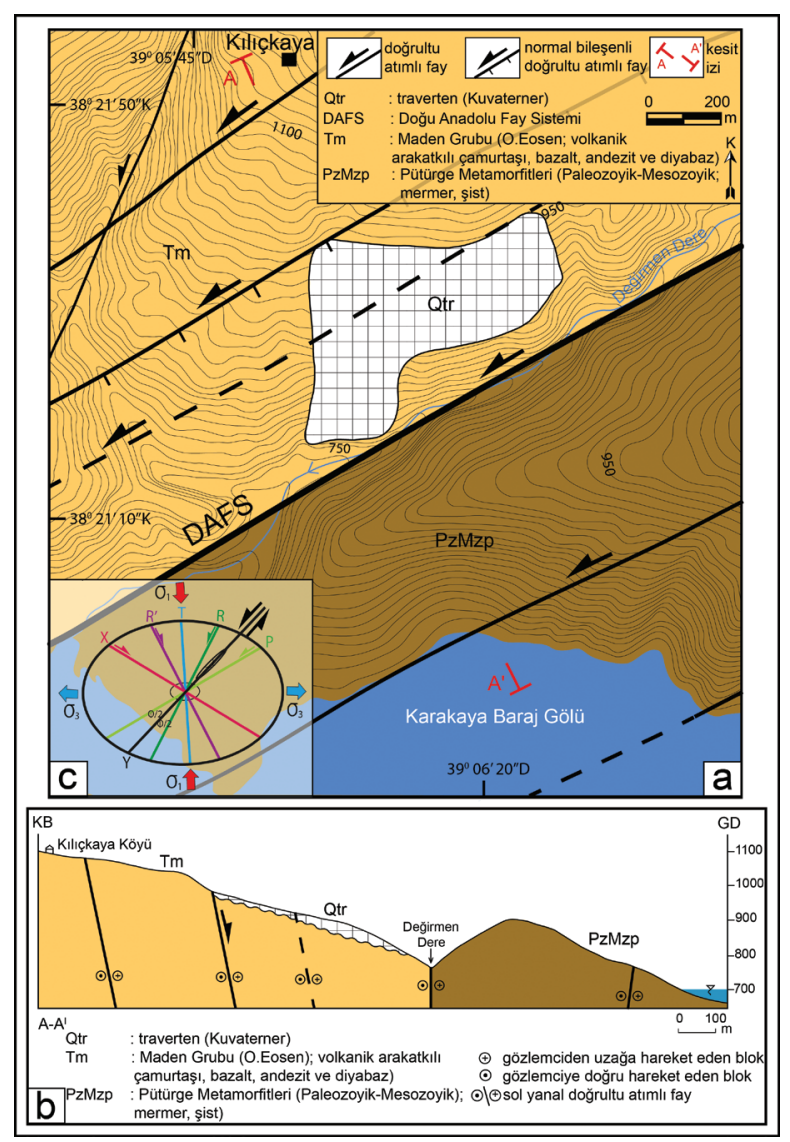

Şekil 3. Traverten çevresinin a- jeolojik haritası; b- enine jeolojik kesiti; c- travertenin deformasyon elipsoidi üzerindeki konumu

Figure 3. a- geological map and, b-cross section of travertine area; c-position on the deformation elipsoid of the travertine 


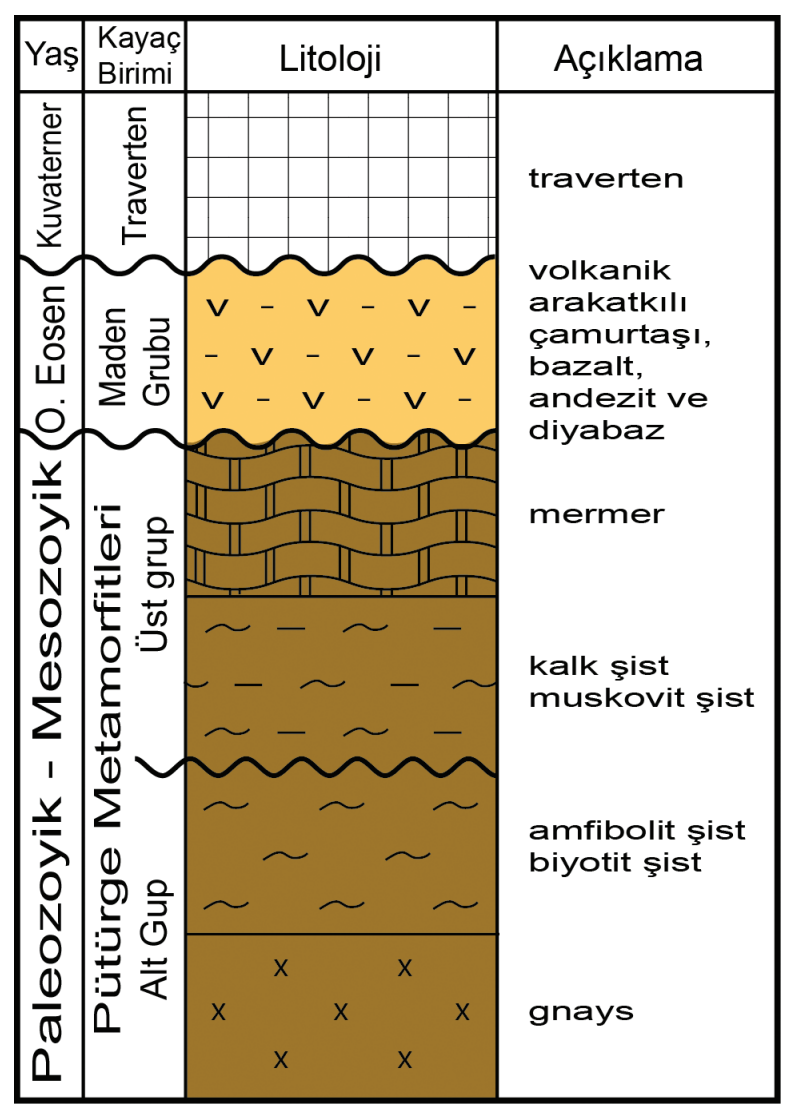

Şekil 4. Traverten yüzleği ve çevresinin genelleştirilmiş stratigrafik dikme kesiti

Figure 4. Generalized stratigraphic columnar section of travertine area

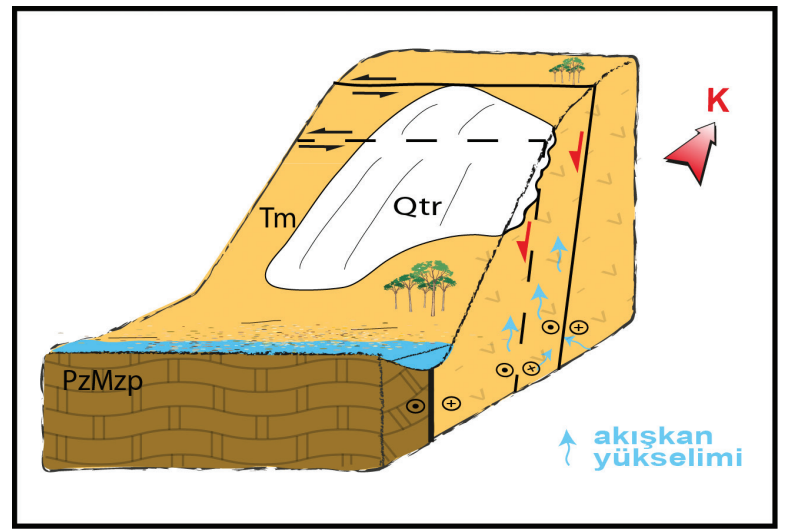

Sekil 5. Travertenin oluşum modeli. Qtr: traverten (Kuvaterner), Tm: Maden Grubu (O.Eosen); volkanik arakatkılı çamurtaşı, bazalt, andezit ve diyabaz), PzMzp: Pütürge Metamorfitleri (Paleozoyik-Mesozoyik); mermer, şist

Figure 5 Blockdiagramshowingtravertineformation model. Qtr: travertine (Quaternary), Tm: Maden Group (M. Eocene); mudstone with volcanic interbedded, basalt, andesite and diabase), PzMzp: Pütürge Metamorphics (Paleozoic-Mesozoic); marble, schist

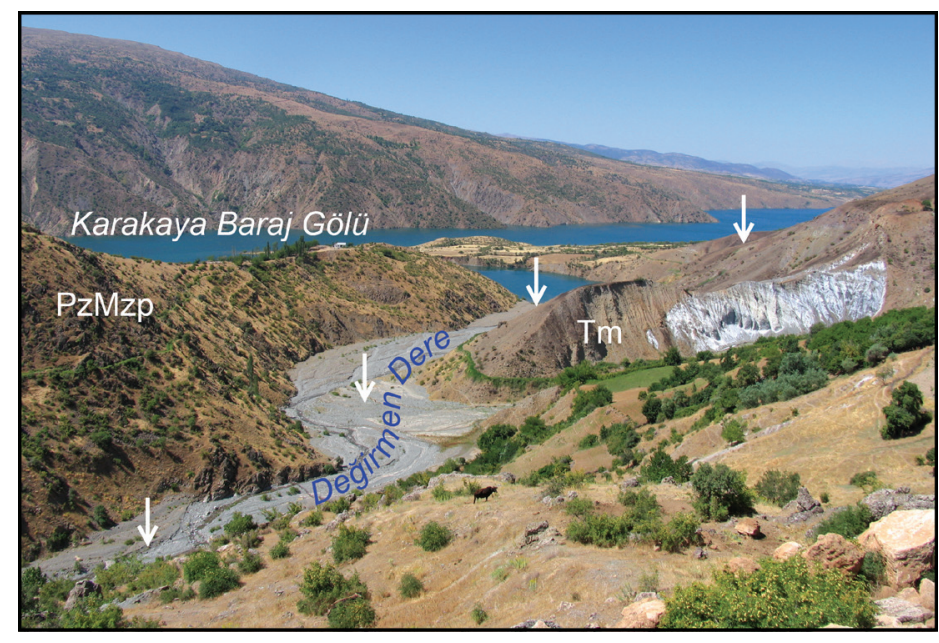

Şekil 6. Sivrice Fay Zonu ana kırı̆̆ının denetlediği Değirmen Dere boyunca Pütürge Metamorfitleri (PzMzp) ile Maden Grubu'nun (Tm) yanyana gelişi. Bakış güneybatıya.

Figure 6. Juxtaposition of Pütürge Metamorphics (Paleozoic-Mesozoic) and Maden Group (M. Eocene) along main fracture of Sivrice fault zone that control the Değirmen stream. View to $S W$ 
Çizelge 1. Traverten örneklerinin element konsantrasyonları

Table 1. Element concentrations of travertine samples

\begin{tabular}{rccccccc}
\hline Kılıçkaya & Ca & Si & Al & Fe & Mg & Mn & Sr \\
\cline { 2 - 7 } Örnek No & & & & $(\mathrm{ppm})$ & & & \\
\hline KK-2 & 382361 & 1028 & 212 & 1049 & 7961 & 542 & 5983 \\
KK-4 & 378216 & 3085 & 900 & 1049 & 7358 & 310 & 6046 \\
KK-5 & 382647 & 2337 & 159 & 560 & 8021 & $<78$ & 3626 \\
KK-6 & 381075 & 4721 & 1694 & 699 & 7538 & $<78$ & 2133 \\
KK-7 & 385220 & 28045 & 582 & 490 & 5428 & $<78$ & 3910 \\
\hline
\end{tabular}

\section{U-Th YAŞLARI}

Uranyum-Toryum yaş analizi tekniğinin genel prensipleri için Smart (1991) esas alınmıştır. Teorik olarak U, kalsiyum içeren doğal sularda kolaylıkla çözülebilir ve kolaylıkla anyon kompleksleri oluşturur. Buna karşın Th, çözeltide hızlıca hidroliz olur vekil mineralleri ile diğer katı yüzeyler üzerine sıkıca adsorblanır (tutunur). Yani U, kalsiyum karbonatın $\left(\mathrm{CaCO}_{3}\right)$ kimyasal ya da biyolojik çökelmesi sırasında, aynı zamanda çökelmekte ve kalsit kristalleri arasında korunmaktadır. Ancak Th, çökelmemektedir ve doğal sulardaki Th miktarı, dikkate alınmamaktadır. Bundan dolay1 ana izotop ${ }^{234} \mathrm{U}$ 'a karşın ${ }^{230} \mathrm{Th}$ eksikliği vardır. Zaman içinde ${ }^{230} \mathrm{Th} /{ }^{234} \mathrm{U}$ oranı eşitlik sağlanıncaya kadar kademeli olarak artar. Çünkü ${ }^{234} U$ ve ${ }^{238} U$ arasında da bir eşitsizlik vardır ve ${ }^{234}$ U'nun ayrışması, zamanla ${ }^{230} \mathrm{Th} /{ }^{234} \mathrm{U}$ oranını yavaş yavaş artırır.

Uranyum serisi yaş tekniğinin herhangi bir karbonat örneğinde başarılı uygulanabilmesi, aşağıdaki varsayımlar ve kriterler üzerine inşa edilmiştir. 1) Karbonat örneği aynı çözeltiden hemen kristallenmiştir. 2) Depolanma sırasında kristallerde ${ }^{230} \mathrm{Th}$ mevcut olmayip ve tane yüzeylerinde toryum, ${ }^{232} \mathrm{Th}$ 'dir. Bundan dolay1 bu uzun ömürlü izotop, sonradan gelen toryum kirliliğini izlemek için kullanılabilir. Eğer ${ }^{230} \mathrm{Th} /{ }^{232} \mathrm{Th}$ oran1 20 'den düşük ise ${ }^{230} \mathrm{Th}$ için düzeltme gereklidir; onun için kırıntılı ve bol gözenekli örneklerden kaçınmak gerekir. $\mathrm{Bu}$ düzeltme için değişik yöntemler kullanılmaktadır. 3) Sistem, çökelme tamamlandıktan sonraki uranyum ve toryum dolaşımına kapalıdır. Rekristalleşme, ikincil kristalleşme ve yüksek porozite belirtileri gösteren örneklerden kaçınılmalıdır. Smart (1991)'a göre U-Th yaş metodu, özellikle 400.000 y1l ila 5.000 yıl arasında uygulanabilir.

Traverten sahasından alınan 3 adet traverten örneği U-Th yöntemi ile yaşlandırılmıştır (Çizelge 3). KK-1 örneğinden $29.245 \pm 0.621$ by, KK-6 örneğinden $16.087 \pm 0.380$ by ve KK-7 örneğinden ise $30.861 \pm 0.491$ by yaşları elde edilmiştir. $\mathrm{Bu}$ yaş verilerine göre traverten sahasında günümüzden en azından $30.861 \pm 0.491$ by önce traverten çökelimi başlamıştır. Bu yaş, Holosen (MIS 3, Marine Isotope Stage)'e denk gelmektedir. 
Çizelge 2. Traverten örneklerinin $\delta^{13} \mathrm{C}$ ve $\delta^{18} \mathrm{O}$ duraylı izotop değerleri

Table 2. $\delta^{13} \mathrm{C}$ ve $\delta^{18} \mathrm{O}$ stable isotope values of travertine samples

\begin{tabular}{cccc}
\hline Kılıçkaya & Traverten Tipi & $\mathbf{d}^{13} \mathbf{C}(\mathbf{P D B})$ & $\mathbf{d}^{\mathbf{1 8}} \mathbf{O}(\mathbf{P D B})$ \\
\hline Örnek No & Tabakalı & 5,4 & $-9,3$ \\
KK-1 & Tabakalı & 6,7 & $-9,6$ \\
KK-2 & Tabakalı & 3,5 & $-9,5$ \\
KK-3 & Laminalı & 6,2 & $-8,1$ \\
KK-5 & Damar & 4,3 & $-9,2$ \\
KK-6 & Akmataş & 5,2 & $-8,8$ \\
KK-7 & Tabakalı & 4,9 & $-9,2$ \\
\hline
\end{tabular}

Çizelge 3. Travertenlerinin U-Th yaşlandırma analiz sonucu

Table 3. U-Th dating results of travertine samples

\begin{tabular}{|c|l|l|l|}
\hline & \multicolumn{3}{|c|}{ Örnek No } \\
\hline & KK-1 & KK-6 & KK-7 \\
\hline $\mathbf{2 3 8}^{\mathrm{U}} \mathbf{p p m}$ & 2,067 & 0.9686 & 1,816 \\
\hline \pm & 0.0136 & 0.0043 & 0.0069 \\
\hline $\mathbf{2 3 2}^{\text {Th }} \mathbf{p p m}$ & 0.053 & 0.0322 & 0.071 \\
\hline \pm & 0.0004 & 0.0003 & 0.0006 \\
\hline $\mathbf{2 3 4}^{\mathrm{U}} / \mathbf{2 3 8}^{\mathbf{U}}$ & 1,0243 & 1,0525 & 1,0212 \\
\hline \pm & 0.012 & 0.007 & 0.0063 \\
\hline $\mathbf{2 3 0}^{\text {Th}} \mathbf{2 3 4}^{\mathbf{U}}$ & 0.2403 & 0.1445 & 0.2542 \\
\hline \pm & 0.0034 & 0.003 & 0.0029 \\
\hline $\mathbf{2 3 0}^{\text {Th}} / \mathbf{2 3 8}^{\mathbf{U}}$ & 0.2462 & 0.1521 & 0.2596 \\
\hline \pm & 0.0028 & 0.0031 & 0.0027 \\
\hline $\mathbf{2 3 0}^{\text {Th }} / \mathbf{2 3 2}^{\text {Th }}$ & 29,3567 & 13,9661 & 20,3006 \\
\hline \pm & 0.368 & 0.3169 & 0.2774 \\
\hline Hesaplanan Yaş (binyl) & 29,855 & 16,952 & 31,864 \\
\hline Hata & 0.484 & 0.383 & 0.432 \\
\hline Düzeltilen Yaş (binyll) & 29,245 & 16,087 & 30,861 \\
\hline Hata & 0.621 & 0.38 & 0.491 \\
\hline & & & \\
\hline
\end{tabular}




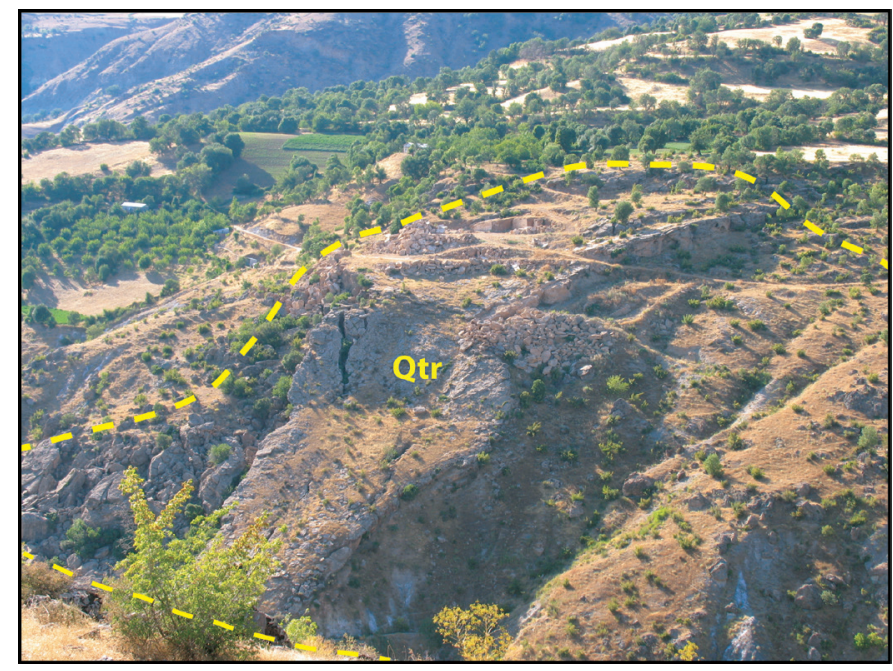

Şekil 7. Traverten yüzleğinden bir arazi görünümü. Yamaç duraysızlı̆̆ı nedeniyle, traverten kütlesi yer yer parçalanmıştır. Bakış kuzeybatıya

Figure 7. Field view of travertine. Travertine outcrop shattered due to slope instability. View to NW

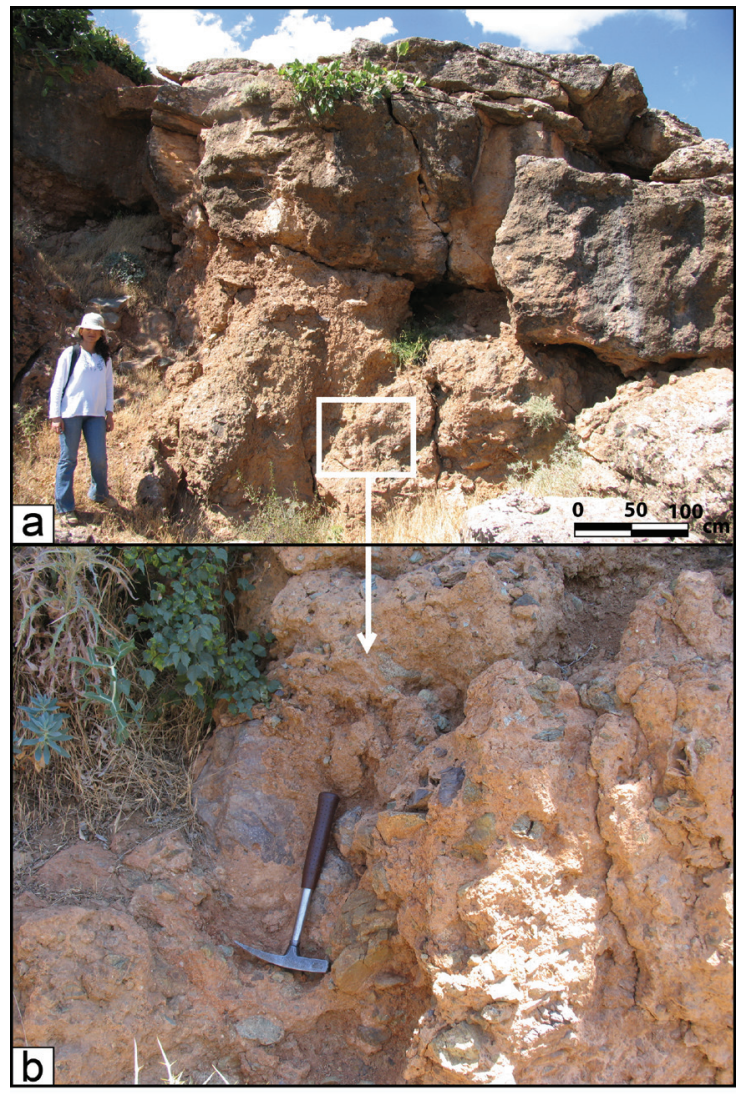

Şekil 8. a- Traverten istifinin tabanı. İstif, üzerinde uyumsuz olarak yer aldığı Maden Grubu üzerinde kırıntılı bir seviye ile başlar ve yukarı doğru masif travertenlere geçer; b- a'daki kutucukta bulunan kırıntılı seviyenin yakından görünümü

Figure 8. $\quad$ a-The bottom of the travertine sequence. This sequence start on the Maden Group with a detritial level and continue with massif travertine; $b$-close-view of the rectangular on the (a) 


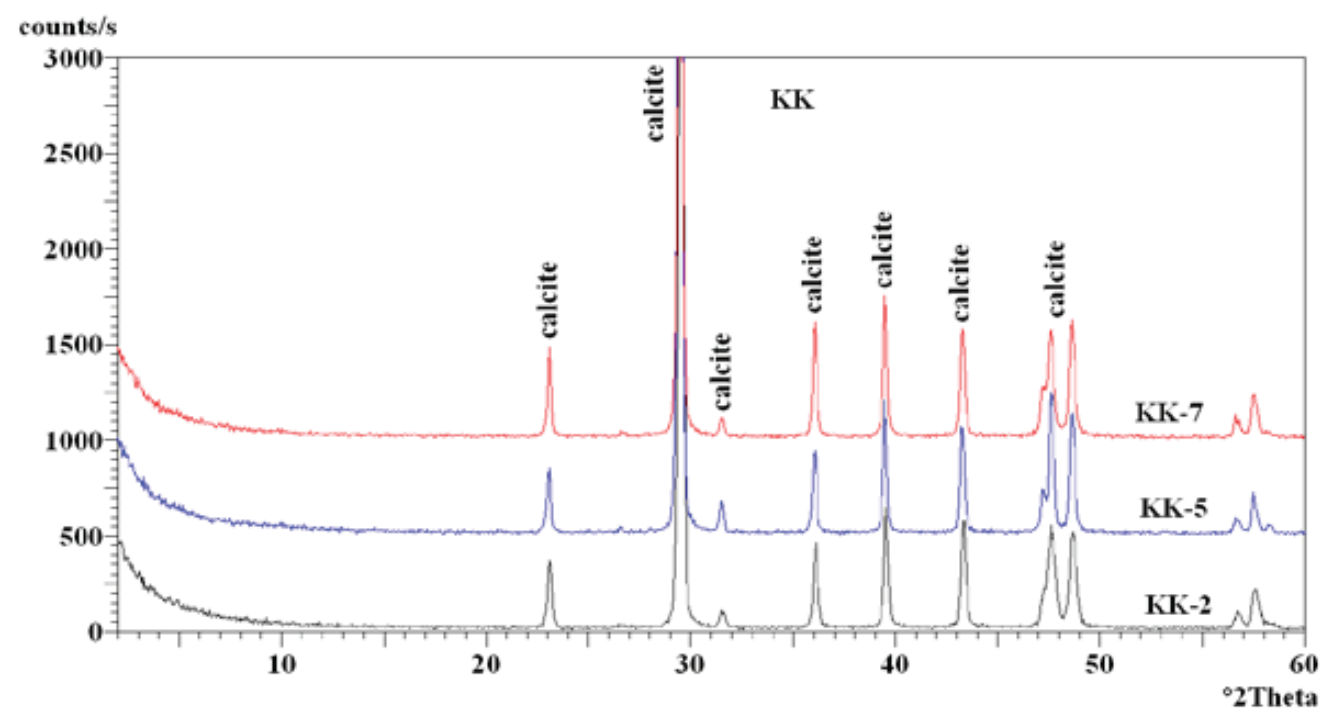

Şekil 9. Traverten örneklerinin XRD difraktogramı

Figure 9. XRD difractograme of travertine samples

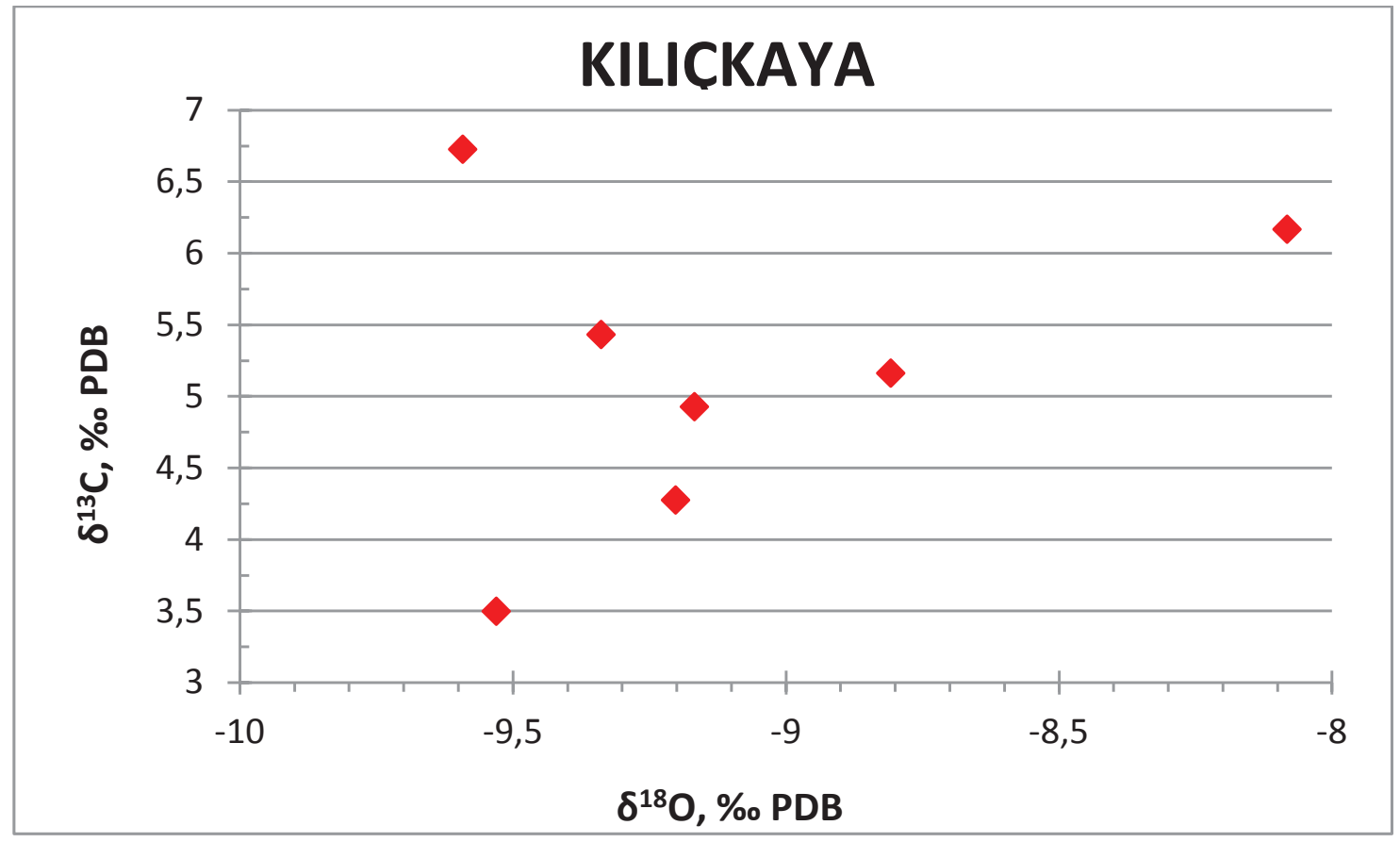

Şekil 10. Traverten örneklerinin $\delta^{13} \mathrm{C}$ ve $\delta^{18} \mathrm{O}$ izotop değerleri grafik dağılımı

Figure 10. $\delta^{13} \mathrm{C}$ and $\delta^{18} \mathrm{O}$ isotope values of travertine samples 


\section{SONUÇLAR}

Traverten yüzleği, büyük bir makaslama zonu olan sol yanal doğrultu atımlı Doğu Anadolu Fay Sistemi'ni oluşturan fay zonlarından Sivrice Fay Zonu'nun aktivitesiyle ilişkili olarak genişlemeli bir alanda çökelmiştir. Traverten oluşumuna kaynak sağlayan ana kaya, Pütürge Metamorfitleri'dir. Farklı litolojilerden oluşan birimin mermerleri, $\mathrm{CaCO}_{3}$ kaynağıdır.

Morfolojik sinıflamaya göre, fay önü traverteni olarak çökelmiştir. Travertenin oluşmasını sağlayan kırıklar, deformasyon elipsoidiüzerineyerleştirildiğinde Ykırığı̈uzerinde depolanmış oldukları anlaşı1ır. Travertenlerin geliştiği sol yanal doğrultu atımlı fayların normal bileşene sahip olmasından dolayı düşen bloklarda, normal faylarda görülen tavan bloğu deformasyonuna tanık olunur. Bu deformasyonla ilişkili genişleme, traverten çökelten $\mathrm{Ca}\left(\mathrm{HCO}_{3}\right)_{2}{ }_{2}{ }_{1}$ suların yeryüzüne çıkmasına olanak sağlar.

YapılanXRDanalizlerinegöretravertenler, tamamen kalsitten meydana gelmişlerdir ve eser miktarda kuvars içermektedirler. Jeokimyasal verilere göre incelenen travertenler, termojen kökenlidir.

Yaş verileri, neotektonik dönemin Doğu Anadolu Bölgesi için öngörülen sınırları içinde yer aldığ 1 ve traverten oluşumunun, doğrultu atımlı sistemin bu dönemdeki etkinliğiyle ilişkili olduğu şeklinde yorumlanmıştır.

\section{KATKI BELIRTME}

$\mathrm{Bu}$ çalışma, TÜBİTAK 110Y172 no'lu proje kapsamında desteklenmiştir. Yazar, ayrıca Fırat Üniversitesi'nden Ercan AKSOY ve Pamukkale Üniversitesi'nden Mehmet ÖZKUL'a teşekkür eder.

\section{EXTENDED SUMMARY}

Travertine is a hard compact limestone deposited from solution by springs or percolating waters that can formed under chemical and/or biochemical prosses around karstic and thermal springs. Primary mineral of travertines are calcite. There is worldwide association of travertine deposits with tectonically and seismically active zones. Because, faulting plays a key role in the transport of hydrothermal fluids forming travertines. Therefore, travertines reflect some signs of regional tectonics. Because of many travertines have been depositing since the Pleistocene and, the occurence of active and inactive travertines indicates the tectonic activity continues or continued into the recent past. Wherefore travertines contain syndepositional and postdepositional tectonic structures, provide important information about syndepositional and postdepositional tectonic.

The East Anatolian fault system (EAFS) of left lateral strike-slip is second important neotectonic structure of Turkey. In this study the travertine occurrence is located on the Sivrice fault zone, which is one the significant zone of the EAFS and precipitated on a $S$ to $S W$-facing slope, $20 \mathrm{~km} \mathrm{SW}$ of the Sivrice town (Elazig) in accordance with the slope topography.

The Maden Group of Middle Eocene age, on which the travertine occurrence took place, composed mostly of mudstones with volcanic intercalations, andesite, basalt and diabase dykes that cut them. The Pütürge Metamorfics that play role as a basement rock are represented by calcschist and marble around their Sivrice exposures. Lithology of the Pütürge Metamorfics and, the fractured structure due to left lateral strike-slip Sivrice Fault Zone play an important role on the travertine formation. As the travertine exposures located along the left lateral strikeslip fault zone with normal component has been 
precipitated in front of a fault, under appropriate conditions that formed by faults and bedrock, they have been evaluated as 'fault-front travertines' depending on the morphological classification. The bottom of the travertine sequence starts on the Maden Group with a detritial level and then passes into massif travertine.

According to XRD analysis travertines completely composed of calcite and, contain quartz slightly. The most abundant element concentrations of the travertine samples are: Ca: 378216-385220 ppm, Mg: 5428-8021 ppm, Sr: 2133-6046 ppm. The $\delta^{13} \mathrm{C}$ values range from $+3,5$ to $+6,7$ (\%o $P D B)$, while the $\delta^{18} \mathrm{O}$ values are between -8.1 and -9.6 (\%oPDB). These geochemical signatures indicate that the travertines studied are of thermogene origin. Travertine precipitation began at least $30.86 \pm$ $0.49 \mathrm{ka}$ ago with respect to today in the field based on the U-Th age data. This age data is suitable with predetermined neotectonic period of Eastern Anatolia and travertine occurrence is associated with the activities of the strike-slip system in this period. Interpreted that take place within the limits prescribed for the Eastern Anatolia Region of neotectonic period and.

\section{DEĞINIILEN BELGELER}

Aksoy, E., İnceöz, M. and Koçyiğit, A., 2007. Lake Hazar basin: A negative flower structure on the East Anatolian Fault System (EAFS), SE Turkey. Turkish Journal of Earth Sciences, Vol. 16, 319338.

Aksoy, E., Özkul, M. ve Çolak, S., 2011. Doğu Anadolu Fay Sistemi'nin Kuzeydoğu Bölümündeki Travertenlerin Neotektonik Önemi. TÜBITAK Raporu, 66 s. (Basılmamış).

Altunel, E., 1994. Active Tectonics and the Evolution of Quaternary travertines at Pamukkale, Western Turkey. PhD Thesis, University of Bristol, Department of Geology, 236 p.
Altunel, E., 1996. Pamukkale Travertenlerinin Morfolojik Özellikleri, Yaşları ve Neotektonik Önemleri. MTA Dergisi, 118, 47-64.

Altunel, E. and Hancock, P.L., 1993a. Morphology and Structural Setting of Quaternary Travertines at Pamukkale, Turkey. Geological Journal, 28, 335346.

Altunel, E. and Hancock, P.L., 1993b. Active Fissuring and faulting in Quaternary Travertines at Pamukkale, Western Turkey. Zeitschrift Geomorphologie, Supplementary 94, 285-302.

Arpat, E. ve Şaroğlu, F., 1972. Doğu Anadolu Fayı ile ilgili bazı gözlem ve düşünceler. MTA Bült., 73, 1-9.

Ayaz, E., 1998. Sıcak Çermik (Yıldızeli-Sivas) Yöresindeki Traverten Sahalarının Jeolojisi ve Travertenlerin Endüstriyel Özellikleri. Doktora Tezi, Sivas Cumhuriyet Üniversitesi Fen Bilimleri Enstitüsü, 157 s. (yayınlanmamış).

Ayaz, E., 2002a. Travertenlerde Gözlenen Morfolojik Yapılar ve Tabiat Varlığı Olarak Önemleri. Cumhuriyet Üniversitesi Mühendislik Fakültesi Dergisi, Seri A-Yerbilimleri C.19, S.2, 123-134.

Bates, R. L. and Jackson, J. A., 1980. Glossary of Geology (Second Edition). American Geology Institute Falls Church, Virginia, 751.

Chafetz, H. S. and Folk, R. L., 1984. Travertines, depositional morphology and the bacterially constructed constituents. Journal of Sedimantary Petrology, 54, 289-316.

Cipriani, N., Malesani, P., Vannucci, S., 1977. I travertini dell'Italia centrale, Boll. Serv. Geol. Ital., 98, 85-115.

Çakır, Z., 1996. Tectonic Significance of Quaternary Travertine Deposits in the Gediz and Menderes Grabens. Western Turkey. Yüksek Lisans Tezi, Bristol Üniversitesi, UK.

Çakır, Z., 1999. Along-strike discontinuity of active normal faults and its Influence on Quaternary travertine deposition: Examples from western Turkey, Tr. J. of Earth Sciences, 8, 67-80.

Çelik, H., 2003. Mastar Dağı (Elazığ GD’su) çevresinin stratigrafik ve tektonik özellikleri. Doktora Tezi, Fırat Üniversitesi Fen Bilimleri Enstitüsü, 95 s. (yayımlanmamış). 
Çolak Erol, S., 2014. Doğu Anadolu Fay Sistemi'nin kuzeydoğu bölümündeki travertenlerin neotektonik önemi. Doktora Tezi, Frrat Üniversitesi Fen Bilimleri Enstitüsü, 184s. (yayımlanmamış).

Çolak Erol, S., Özkul, M., Aksoy, E., Kele, S. and Ghaleb, B., 2015. Travertine occurences along major strike-slip fault zones: Structural, depositional and geochemical constraints from the Eastern Anatolian Fault System (EAFS), Turkey. Geodinamica Acta, Volume 27, Issue 2-3, pp. 154173.

Duchi, V., Giordano, M.V. and Martini, M., 1978. Riesame del problema della precipitazione di calcite od aragonite da soluzione naturali, Rend. Soc. Ital. Miner. Pet., 34, 605-618

Erdem, E., 1994. Pütürge (Malatya) Metamorfitlerinin petrografik ve petrolojik özellikleri. Doktora Tezi, Fırat Üniversitesi, Fen Bilimleri Enstitüsü, $119 \mathrm{~s}$.

Folk, R., 1994. Interaction between bacteria, nannobacteria, and mineral precipitation in hot springs of centrai Italy. Geographic physique et Quaternaria, 48, 3, 233-246.

Fouke, B.W., Farmer, J.D., Des Marais, D.J., Pratt, L., Sturchio, N.C., Burns, P.C. and Discipulo, M.K., 2000. Depositional facies and aqueoussolid geochemistry of travertinedepositing hot springs (Angel Terrace, Mammoth Hot Springs, Yellowstone National Park, USA). J. Sediment. Res., 70, 265-285.

Guo, L., and Riding, R., 1998. Hot-springs travertine facies and sequences, Late Pleistocene, Rapolano Terme, Italy. Sedimentology, 45, 163-180.

Gülen, L., Barka, A. ve Toksöz, M. N., 1987. Kıtaların çarpışması ve ilgili kompleks deformasyon, Maraş üçlü eklemi ve çevre yapıları, Yerbilimleri, 14, 319-336.

Gürsoy, H., Tatar, O., Piper, J. D. A., Heimann, A. and Mesci, L., 2003. Neotectonic deformation linking the east Anatolian and Karatas-Osmaniye intracontinental transform fault zones in the Gulf of İskenderun, southern Turkey, deduced from paleomagnetic study of the Ceyhan-Osmaniye volcanics, Tectonics, vol. 22 , no. 6,1067 . Hall, R., 1976. Ophiolite emplacement and the evolution of the Taurus Suture Zone, south-eastern Turkey, Bull.Geol.Soc.Ame., 87, 1078-88.
Jackson, J. and McKenzie, D., 1984. Active tectonics of the Alpine-Himalayan belt between western Turkey and Pakistan, Geoph. J. Royal Astr. Soc., 77, 185-264.

Julia, R., 1983. Travertines. In: P.A. Scholle, D.G. Bebout and C.H. Moore (Editors), Carbonate depositional Environments. Am Assoc. Petrol. Geol. Mem. 33, 64-72.

Karabacak, V., 2002. Ihlara Vadisi civarındaki traverten oluşumları ve tektonik önemleri. Yüksek Lisans Tezi, Eskişehir Osmangazi Üniversitesi Fen Bilimleri Enstitüsü, $70 \mathrm{~s}$. (yayınlanmamış).

Kele, S., Demény, A., Siklósy, Z., Németh, T., Mária, T.B., Kovács, M., 2008. Chemical and stable isotope compositions of recent hot-water travertines and associated thermal waters, from Egerszalók, Hungary: depositional facies and nonequilibrium fractionations. Sedimentary Geology 211, 53-72.

Kele, S., Özkul, M., Gökgöz, A., Fórizs, I., Baykara, M.O., Alçiçek, M.C., Németh, T., 2011. Stable isotope geochemical and facies study of Pamukkale travertines: new evidences of low-temperature non-equilibrium calcite-water fractionation. Sedimentary Geology 238, 191-212.

Koçyiğit, A., Aksoy, E. and İnceöz, M., 2003. Basic neotectonic characteristics of the Sivrice Fault Zone in the Sivrice-Palu area, East Anatolian Fault System (EAFS), Turkey. International Workshop on the North Anatolian, East Anatolian and Dead Sea Fault systems: Recent progress in Tectonics and Paleoseismology, 31 August to 12 September 2003, METU-Ankara-Turkey. Pre-International workshop excursion guide-book, $20 \mathrm{p}$.

Lyberis, N., Yürür, T., Chorowıcz, J., Kasapoğlu, E. and Gündoğdu, N., 1992. The East Anatolian Fault: An Oblique collisional belt. Tectonophysics, 204, 1-15.

Mesci, B.L., 2004. Sicak Çermik ve Yakın Yöresindeki (Sivas) Travertenlerin Gelişimi ve Aktif Tektonikle İlişkisi. Doktora Tezi, Sivas Cumhuriyet Üniversitesi Fen Bilimleri Enstitüsü, 245 s. (yayınlanmamış).

Mesci, B.L., 2013b. Active Tectonics of the Ortaköy Fissure-Ridge-Type Travertines: Implications for the Quaternary Stress State of the Neotectonic 
Structures of the Central Anatolia, Turkey. Geodinamica Acta, 25, 12-25.

Mesci, B.L., Gürsoy, H. and Tatar, O., 2008. The Evolution of Travertine Masses in the Sivas Area (Central Turkey) and Their Relationship to Active Tectonics. Turkish Journal of Earth Sciences, 17, pp. 219-240.

Muehlberger, W.R. and Gordon, M.B., 1987. Observation on the coplexity of The East Anatolian Fault, Turkey. Jour. Structural Geology, 9/7, 899-903.

Özkul, M., Gökgöz, A., and Horvatinčić, N., 2010. Depositional properties and geochemistry of Holocene perched springline tufa deposits and associated spring waters: A case study from the Denizli province, Western Turkey. In: Pedley, H.M. (Ed.), Tufas and Speleothems: Unravelling the Microbial and Physical Controls. The Geological Society, London. Special Publications 336, pp. 245-262.

Özkul, M., Kele, S., Gökgöz, A., Shen, C.C., Jones, B., Baykara, M.O., Fórizs, I., Nemeth, T., Chang, Y.W., and Alçiçek, M.C., 2013. Comparison of the Quaternary travertine sites in the Denizli Extensional Basin based on their depositional and geochemical data. Sedimentary Geology, 294, 179-204.

Özkul, M., Gökgöz, A., Kele, S., Baykara, M.O., Shen, C.-C., Chang, Y.-W., Kaya, A., Hançer, M., Aratman, C., Akın, T. and Örü, Z., 2014. Sedimentological and geochemical characteristics of a fluvial travertine: a case from the eastern Mediterranean region. Sedimentology, 61, 291318.

Pentecost, A., 2005. Travertine (p. 446). Berlin: Springer Verlag.

Smart, P.L., 1991. Uranium series dating. In: P.L. Smart and P.D. Francis (Eds.). Quaternary dating Methods-a User's Guide. Qart. Res. Assoc. Tech. Guide. 4, London, pp.45-83.

Sungurlu, O., Perinçek, D., Kurt, G., Tuna, E., Dülger, S., Çelikdemir, E. ve Naz, H., 1985. Elazı̆̆ Hazar - Palu alanının jeolojisi. Petrol Işsleri Genel Müdürlüğü Dergisi, 29, 83-191.

Şaroğlu, F., Emre, Ö. and Kuşçu, İ., 1992b. The East Anatolian fault zones of Turkey, Annales Tectonicae, 6, 99-125.
Şengör, A.M.C., Görür, N. and Şaroğlu, F., 1985. Stirike-slip faulting and related basin formation in zone of tectonic escape: Turkey as a case study. In: "Stirike-slip deformation, basin deformation and sedimentation". Edited by: K.T. Biddle\&N. Christie-Blick. Soc. Econ. Paleont. and Min. Spec. Publ., 37, 227-264.

Uysal, T., Feng, Y., Zhao, J., Altunel, E., Weatherley, D., Karabacak, V., Cengiz, O., Golding, S.D., Lawrence, M.G. and Collerson, K.D., 2007. U-series dating and geochemical tracing of late Quaternary travertines in co-seismic fissures, Earth and Planetary Science Letters, 257, pp. 450-462.

Uysal, I. T., Feng, Y., Zhao, J., Işık, V., Nuriel, P. and Golding, S.D., 2009. Hydrothermal $\mathrm{CO}_{2}$ degassing in seismically active zones during the late Quaternary, Chemical Geology, 265, 442-454.

Westaway, R., 1994. Present-day kinematics of the Middle East and eastern Mediterranean. Jour. Geophys. Res., 99/B6, 12,071-12090.

Westaway, R., 2003. Kinematics of the Middle East and Eastern Mediterranean Updated, Turkish J.Earth Sci. J., 12, 5-46.

Wyatt, A. (ed.), 1986. Challinor's Dictionary of Geology ( $6^{\text {th }}$ Edition). University of Wales Press, Cardiff, pp. 374.

\begin{tabular}{ll}
\hline Makale Geliş Tarihi & $: 15$ Temmuz 2016 \\
Kabul Tarihi & $: 18$ Ağustos 2016 \\
& $:$ 15 July 2016 \\
Received & $:$ 18 August 2016
\end{tabular}


